\title{
Conjunctival Carcinoma pT3 TNM Finding v8
}

National Cancer Institute

\section{Source}

National Cancer Institute. Conjunctival Carcinoma pT3 TNM Finding v8. NCI Thesaurus. Code C140541.

Conjunctival carcinoma with tumor invading adjacent structures (excluding the orbit). (from AJCC 8th Ed.) 